\title{
LEVANTAMENTO DE FORMIGAS (HYMENOPTERA: FORMICIDAE) EM RESIDÊNCIAS DE MANAUS, ESTADO DO AMAZONAS, BRASIL.
}

\author{
Ana Paula Coelho MARQUES ${ }^{1,2}$, Rosaly ALE-ROCHA ${ }^{1}$, José Albertino RAFAEL ${ }^{1}$
}

RESUMO - Apresenta-se os resultados do levantamento de formigas que infestam residências na cidade de Manaus, Amazonas. Comparou-se duas estações do ano (seca e chuvosa), dois períodos de atividade (diurno e noturno) e quatro diferentes cômodos da casa (sala, quarto, cozinha e banheiro). Todas residências estavam infestadas por pelo menos uma espécie de formiga; 21 espécies foram coletadas, sete delas consideradas características de habitats humanos e dessas, três são exóticas. Observou-se maior diversidade durante a época chuvosa e no período noturno. A cozinha foi o cômodo com maior ocorrência e a diversidade foi semelhante entre os cômodos; nenhuma espécie dominante foi observada; Tapinoma melanocephalum foi a espécie mais comum e quase sempre encontrada com outras espécies.

Palavras-chave: Formigas urbanas, Manaus, Brasil.

House Infesting Ants (Hymenoptera: Formicidae) in the City of Manaus, Amazonas, Brazil.

ABSTRACT - This research shows the results of a study of house infesting ants in the city of Manaus, Amazonas. It was compared two seasons (dry and rainy), two activity periods (day and night) and four different rooms of the house (living-room, bedroom, kitchen and bathroom). All the residences were infested with at least one type of ant. Twenty one species were collected, seven of them are considered as characteristic of human habitats, and of these three are exotic ants. The larger diversity was observed during the rainy season and during the night. The kitchen was the room with larger occurrence of ants, whereas the diversity was similar among the rooms. Tapinoma melanocephalum was the most common species, being found frequently with other ant species.

Key-words: Urban ants, Manaus, Brazil.

\section{INTRODUÇÃO}

As formigas são insetos sociais e ocorrem, praticamente, em todos os ambientes terrestres, exceto nos pólos. Como qualquer ambiente natural, os ambientes artificiais podem ser colonizados e explorados por várias espécies de formigas. Assim, algumas espécies encontram-se associadas ao homem e convivem em suas residências (Bueno \& CamposFarinha, 1999).
Formigas que ocorrem no ambiente urbano são consideradas destrutivas ou prejudiciais à saúde humana à conservação e qualidade de alimentos, instalações elétricas e equipamentos eletrônicos (Delabie et al. 1995). As formigas que infestam residências tem recebido atenção crescente em todo o mundo mas apenas recentemente no Brasil (Brown, 1964; Fowler et al.1992, 1993; Ketelhut et al. 1993; Delabie et al. 1995).

INPA, Coordenação de Pesquisas em Entomologia, CPEN - Caixa Postal 478 CEP 69011-970 Manaus - AM.

${ }^{2}$ Bolsista $\mathrm{CNPq} / \mathrm{PIBIC}$ 
Segundo Delabie et al. (1995), as condições climáticas favoráveis e as características das habitações humanas nos trópicos favorecem uma alta freqüência de ocorrência de formigas em residências nas regióes tropicais da América do Sul se comparado com residências das regiões temperadas. Este trabalho teve como objetivo identificar as principais espécies de formigas presentes em residências na cidade de Manaus (AM) comparandose quatro coletas, duas na estação seca e duas na chuvosa, horário diurno e noturno e diferentes cômodos das residências.

\section{MATERIAL E MÉTODOS}

Foram feitas quatro coletas: outubro (estação seca) e dezembro (início da estação chuvosa) de 1999, março (estação chuvosa) e maio (início da estação seca) de 2000 . Foram amostradas 28 residências de Manaus ( $02^{\circ} 53^{\prime} \mathrm{S}$; $9^{\circ} 53^{\prime} \mathrm{W}$ ), escolhidas aleatoriamente. As formigas foram coletadas utilizando-se tubos de vidro $(50 \times 7 \mathrm{~mm})$ contendo melaço de cana a $10 \%$ como isca. Os cômodos amostrados (sala, quarto, cozinha e banheiro) receberam três tubos cada, colocados durante o turno matutino (intervalo entre 6:00 e 12:00h), e noturno (entre 18:00 e 24:00h), sendo retirados após 1-2 horas de exposição, quando uma quantidade suficiente de formigas havia sido atraída pela isca. Os tubos foram transportados para a Coordenação de Pesquisas em Entomologia do INPA para triagem de morfoespécies e posteriormente enviados ao Laboratório de Mirmecologia da CEPLAC, Itabuna, Bahia para identificação. O material testemunho foi depositado na Coleção de Invertebrados do INPA e parte na coleção do Dr. Jacques Delabie (CEPLAC, BA).

Os dados foram analisados considerando-se uma residência ou cômodo como a unidade amostral. Os gráficos e tabelas foram construídos utilizando-se planilha do Microsoft Excel,

\section{RESULTADOS E DISCUSSÃO}

Todas as residências amostradas estavam infestadas por pelo menos uma espécie de formiga. A infestação de residências por formigas é esperada visto que grande número de espécies urbanas de formigas constróem seus ninhos e alimentam-se em residências devido ao acesso permanente ao alimento, ausência de predadores naturais e condições ambientais estáveis (apenas pequenas mudanças na temperatura e umidade) (Vepsalainen \& Pisarski, 1982). A ocupação de ambientes internos por algumas espécies de formigas pode ser devido a escassez de alimentos em ambientes externos e a oferta deles nos ambientes internos, levando à migração dessas espécies das áreas verdes e estabelecimento de suas colônias dentro das casas (Martínez et al., 1997). Formigas que adaptaramse ao habitat doméstico formam colônias tipicamente pequenas e freqüentemente ajustam seus hábitos alimentares à variedade de alimentos disponível no meio humano 
(Robinson, 1996).

Alguns pontos são especialmente relevantes para o entendimento da facilidade de dispersão e infestação das formigas domiciliares. Dentre eles estão a poliginia, populações unicoloniais, mudança freqüente do local do ninho, alta taxa de reprodução, reprodução por fragmentação de colônias inclusive sem a necessidade da presença de rainha, pequena estruturação dos ninhos e operárias com tamanho muito pequenos. Esses aspectos associados à variabilidade de espécies implicam grandes dificuldades no controle das formigas domésticas (Bueno \& CamposFarinha, 1999).

Em geral, há apenas uma ou poucas espécies dominantes na mirmecofauna urbana em regiões temperadas, como observado por Martínez et al. (1997) em pesquisa realizada na cidade de Madrid, Espanha. No Brasil, a mirmecofauna em residências, determinada por centenas de coletas em várias cidades, apresentou mais de duas dezenas de espécies diferentes, sendo marcante a predominância de espécies exóticas (Bueno \& Campos-Farinha, 1999). Estas caracterizam-se por uma alta agressividade interespecífica, com o deslocamento das espécies nativas, sendo que as formigas domésticas podem conviver entre elas, uma ser dominante e a outra subdominante, ou haver forte competição (Bueno \& Campos-Farinha, 1999).

Um total de 21 espécies pertencentes a 11 gêneros e 4 subfamílias foram coletadas (Tab. 1).
Dentre as seis espécies de maior freqüência, quatro foram igualmente encontradas por Delabie et al. (1995) entre as mais comuns, em residências no Sul da Bahia, utilizando o mesmo tipo de armadilha/isca, onde obteve 31 espécies numa amostragem de 100 residências.

Das 21 espécies coletadas sete podem ser consideradas verdadeiramente de habitats humanos por terem sido encontradas em diferentes locais e em todas as partes das residências (Tab. 1). Essas espécies foram responsáveis por 91,2 $\%$ do número total de ocorrências. A espécie mais comum foi Tapinoma melanocephalum $\quad(64,3 \%$ de residências infestadas e $32,5 \%$ de ocorrências) (Tab. 1). Três espécies exóticas, Monomorium pharaonis, Paratrechina longicornis e Tapinoma melanocephalum, foram responsáveis por $49,8 \%$ do número total de ocorrências. A maioria dessas espécies tem características em comum tais como poliginia, baixa agressividade intraespecífica e a habilidade de mudar seus ninhos de lugar facilmente (Passera, 1993).

Foram encontradas de uma a seis espécies por residência (Fig. 1). As seis principais espécies tiveram variação na freqüência, comparandose as quatro coletas, a qual foi maior para Camponotus (Tanaemyrmex) sp., Monomorium pharaonis e Solenopsis saevissima (Fig. 3).

$\mathrm{O}$ maior número de ocorrências de formigas foi na cozinha, seguida pela sala, banheiro e quarto (Fig. 2a). A diversidade de 
Tabela 1. Freqüência relativa das espécies de formigas encontradas infestando residências em Manaus.

\begin{tabular}{lcc}
\hline \multicolumn{1}{c}{ Espécies de formigas } & \% de Residências & \% de Ocorrências \\
\hline Tapinoma melanocephalum & 64.3 & 32.5 \\
Pheidole sp. D & 42.9 & 28.8 \\
Paratrechina longicornis & 23.2 & 9.3 \\
Monomorium pharaonis & 22.3 & 8.0 \\
Camponotus (Tanaemyrmex) sp. & 21.4 & 3.8 \\
Solenopsis saevissima & 19.6 & 5.7 \\
Wasmannia auropunctata & 12.5 & 3.1 \\
Pheidole fallax & 8.9 & 1.8 \\
Paratrechina fulva & 8.9 & 3.1 \\
Camponotus (Myrmothrix) atriceps & 4.5 & 0.8 \\
Odontomachus bauri & 3.6 & 0.9 \\
Camponotus (Myrmaphaenus) leydigi & 1.8 & 0.5 \\
Pheidole sp. B & 1.8 & 0.2 \\
Pheidole sp. C & 1.8 & 0.2 \\
Pheidole suzannae & 0.9 & 0.2 \\
Camponotus (Myrmothrix) renggeri & 0.9 & 0.1 \\
Brachymyrmex sp. & 0.9 & 0.1 \\
Gnamptogenys striatula & 0.9 & 0.1 \\
Dorymyrmex pyramicus guyanensis & 0.9 & 0.5 \\
Pheidole sp. & 0.9 & 0.1 \\
Monomorium sp. & 0.9 & 0.1 \\
\hline
\end{tabular}

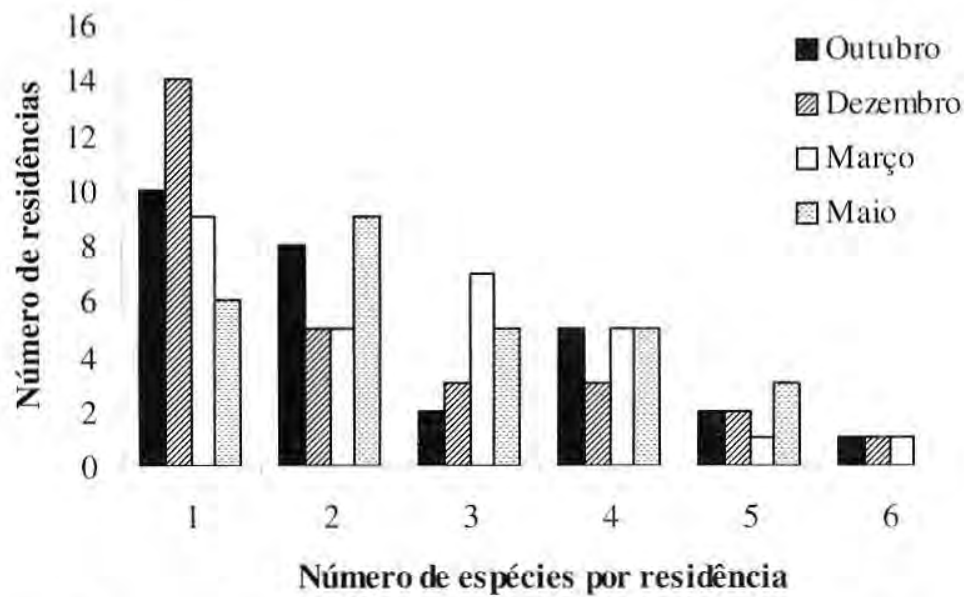

Figura 1. Número de residências infestadas por formigas em função do número de espécies encontradas por residência, em quatro coletas (outubro e dezembro de 1999; março e maio de $2000)$. 
espécies foi semelhante entre os cômodos: a sala apresentou doze espécies, seguida pela cozinha e banheiro, ambos com onze espécies, e por último o quarto com apenas nove espécies (Fig. 2b). Tanto a sala como a cozinha provavelmente oferecem mais possibilidades para a construção de ninhos e também maior oferta de alimentos. Segundo Bueno \& Campos-Farinha (1999), as formigas denominadas tramp species, formigas andarilhas, vivem em íntima associação com o homem e dentro das residências, sua presença na cozinha, despensa e banheiro causa incômodo, além de invadirem e provocarem danos em eletrodomésticos. Em regiões onde é comum a presença de plantas ornamentais nas salas, estas freqüentemente se tornam o principal local infestado da casa, como mostrado por Delabie et al (1995).

Considerando dois turnos (dia e noite), observou-se maior diversidade de espécies durante a noite, principalmente na época mais chuvosa; menor diversidade ocorreu no início da época chuvosa com pouca ou nenhuma diferença no número de espécies entre os dois turnos. As espécies do gênero Camponotus mostraram maior atividade à noite sendo coletadas apenas uma vez durante o dia. O estabelecimento dessas espécies de formigas em ambientes residenciais pode dever-se ao seu hábito noturno, o qual não interfere com a atividade humana e evita a competição com outras espécies
(Delabie et al., 1995).

As espécies Camponotus (Tanaemyrmex) sp. e Solenopsis saevissima, Monomorium pharaonis e Wasmannia auropunctata não foram encontradas infestando uma mesma residência em nenhuma das coletas. Exceto estas espécies, não foi observado efeito antagônico entre a maioria das formigas domiciliares, ocorrendo até quatro espécies em um mesmo cômodo de uma residência, mas não havendo mais de uma espécie por isca.

Linepithema humile, espécie nativa da América do Sul (Argentina e Brasil) e amplamente distribuída em ambientes urbanos das zonas temperadas e subtropical da Austrália, África do Sul, América do Norte e Europa (Robinson, 1996) foi completamente ausente nas coletas. Resultado semelhante obtido por Delabie et al. (1995), indica que assim como na Bahia, a principal diferença entre as comunidades das principais espécies de formigas domésticas infestando residências em Manaus e outras partes do Brasil, é a ausência de $L$. humile, freqüentemente encontrada em ambientes urbanos em outras partes do Brasil (Brown, 1964; Fowler et al. 1993).

\section{AGRADECIMENTOS}

Agradecemos às pessoas que nos permitiram a realização das coletas em suas residências, a Jacques H.C. Delabie (CEPLAC, Itabuna, Bahia) pela identificação do material e a Beatriz Ronchi Teles (CPEN/INPA) pelas sugestões. 


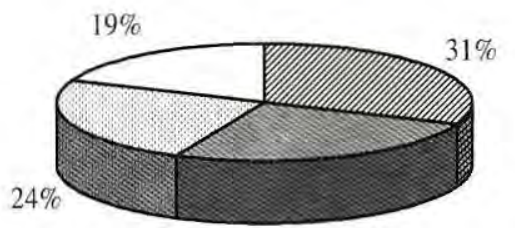

$26 \%$

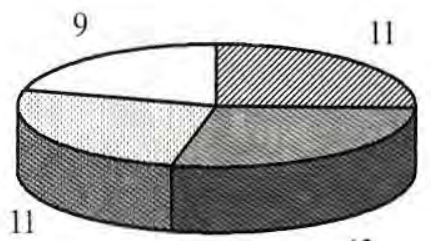

12

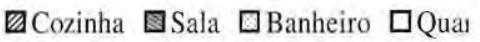

Q Cozinha 1 Sala 0 Banheiro $\square$ Quarto

Figura 2. Percentagem da ocorrência de formigas (a) e número de espécies (b) nos cômodos amostrados.

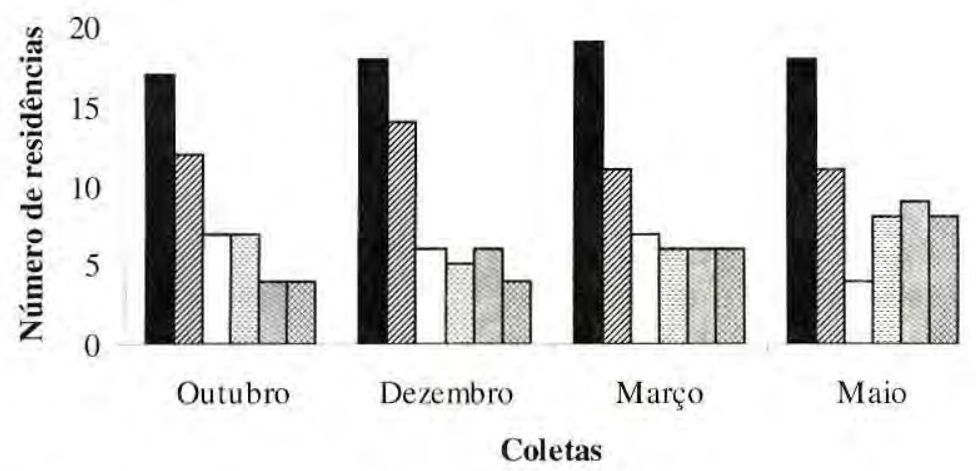

Tapinoma melanocephalum $\quad$ Pheidole sp. D
$\square$ Camponotus (Tanaemyrmex) sp. $⿴$ Paratrechina longicornis

$\square$ Monomorium pharaonis $\quad \square$ Solenopsis saevissima

Figura 3. Espécies de formigas mais abundantes em quatro coletas (outubro e dezembro de 1999; março e maio de 2000) nas residências de Manaus, AM.

\section{Bibliografia citada}

Brown, W. L., Jr. 1964. Some tramp ants of Old World origin collected in Tropical Brazil. Entomol. News 75: 14-15.

Bueno, O. C.; Campos-Farinha, A. E. 1999. As formigas domésticas. In: Insetos e outros invasores de residências. FEALQ, Piracicaba, SP, 460 pp.

Delabie, H. C.; Do Nascimento, I. C.; P. Pacheco \& A. B. Casimiro, 1995. Community structure of house-infesting ants (Hymenoptera: Formicidae) in southern Bahia, Brazil. Florida Entomologist 78(2):
264-270.

Fowler, H.G.; Anaruma Filho \& O. C. Bueno. 1992. Vertical and horizontal foraging: intra and interespecific spatial autocorrelation, tterns in Tapinoma melanocephalum and Monomorium pharaonis (Hymenoptera: Formicidae). Ciência e Cultura 44: 395-397.

Fowler, H.G.; Bueno, O. C. ; T. Sadatsune \& A. C. Montelli. 1993. Ants as potential vectors of pathogens in hospitals in the State of São Paulo, Brazil. Insect Sci. Applic. 14: 367-370.

Ketelhut, S. M.; Fowler, II.G.; Guedes, M.D.; 
Indjai, B.; M. Castellani \& O. C. Bueno. 1993. Formigas caseiras de Rio Claro-SP (Hymenoptera: Formicidae). Resumos, IV International Symposium on Pest Ants, Belo Horizonte, Brasil.

Martínez, M. D. 1997. Urban fauna - Hymenoptera in Madrid households, with special reference to ants (Hymenoptera, Formicidae). Entomofauna 26: 417-428.

Passera, L. 1993. Quels sont les caractères étho-physiologiques des "fourmis vagabondes"? Actes Coll. Insectes Sociaux, 8: 39-45.

Robinson, W. H. 1996. Urban Entomology - Insect and mites pests in the human environment. Chapman \& Hall, London, 430 pp.

Vepsalainen, K. \& Pisarski, B. 1982. The structure of urban ant communities along a geographical gradient from north Finland to Poland. In: Animals in urban environment. Polish Academy of Sciences. Institute of Zoology: 156-168. 